\title{
Subacute Neural Stem Cell Therapy for Traumatic Brain Injury
}

\author{
Matthew T. Harting, M.D. ${ }^{\star}$, LeeAnn E. Sloan, B.S. ${ }^{*}$ Fernando Jimenez, M.S. ${ }^{\star}$, James \\ Baumgartner, M.D. ${ }^{\dagger}$, and Charles S. Cox Jr, M.D. ${ }^{*}, t, 1$ \\ *University of Texas Medical School at Houston, Department of Pediatric Surgery, Houston, \\ Texas \\ ${ }^{\dagger}$ Children's Memorial Hermann Hospital, Houston, Texas
}

\begin{abstract}
Introduction-Traumatic brain injury (TBI) frequently results in devastating and prolonged morbidity. Cellular therapy is a burgeoning field of experimental treatment that has shown promise in the management of many diseases, including TBI. Previous work suggests that certain stem and progenitor cell populations migrate to sites of inflammation and improve functional outcome in rodents after neural injury. Unfortunately, recent study has revealed potential limitations of acute and intravenous stem cell therapy. We studied subacute, direct intracerebral neural stem and progenitor cell (NSC) therapy for TBI.
\end{abstract}

Materials and methods-The NSCs were characterized by flow cytometry and placed (400,000 cells in $50 \mu \mathrm{L} 1 \times$ phosphate-buffered saline) into and around the direct injury area, using stereotactic guidance, of female Sprague Dawley rats $1 \mathrm{wk}$ after undergoing a controlled cortical impact injury. Immunohistochemistry was used to identify cells located in the brain at $48 \mathrm{~h}$ and 2 wk after administration. Motor function was assessed using the neurological severity score, foot fault, rotarod, and beam balance. Cognitive function was assessed using the Morris water maze learning paradigm. Repeated measures analysis of variance with post-hoc analysis were used to determine significance at $P<0.05$.

Results-Immunohistochemistry analysis revealed that 1.4-1.9\% of infused cells remained in the neural tissue at $48 \mathrm{~h}$ and 2 wk post placement. Nearly all cells were located along injection tracks at $48 \mathrm{~h}$. At $2 \mathrm{wk}$ some cell dispersion was apparent. Rotarod motor testing revealed significant increases in maximal speed among NSC-treated rats compared with saline controls at $\mathrm{d}$ 4 (36.4 versus $27.1 \mathrm{rpm}, P<0.05)$ and 5 (35.8 versus $28.9 \mathrm{rpm}, P<0.05)$. All other motor and cognitive evaluations were not significantly different compared to controls.

Conclusions-Placement of NSCs led to the cells incorporating and remaining in the tissues 2 wk after placement. Motor function tests revealed improvements in the ability to run on a rotating rod; however, other motor and cognitive functions were not significantly improved by NSC therapy. Further examination of a dose response and optimization of placement strategy may improve long-term cell survival and maximize functional recovery.

(C) 2009 Elsevier Inc. All rights reserved.

${ }^{1}$ To whom correspondence and reprint requests should be addressed at Department of Pediatric Surgery, University of Texas Medical School at Houston, 6431 Fannin St., MSB 5.254, Houston, TX 77030. charles.s.cox@uth.tmc.edu.. 


\section{Keywords}

traumatic brain injury; neural stem cells; cellular therapy

\section{INTRODUCTION}

Traumatic brain injury (TBI) contributes to 50\% of all trauma-related deaths [1]. Brain injury is frequently involved in the early or late mortality that often results from a polytraumatic insult [2]. When patients do survive after a TBI, the resultant acute and/or chronic deficits in motor, cognitive, behavioral, and/or social functioning leave devastating effects on patients, families, and society [3].

Although many therapeutic interventions have shown preclinical success in altering the cascade of biochemical events that follow TBI, few have been shown to be efficacious in clinical trials [4]. Cellular therapy has shown preclinical promise in the management of TBI. In particular, neural stem/progenitor cells have been shown to mediate motor and cognitive functional recovery when transplanted intracerebrally after TBI [5-8].

The optimal timing of cell delivery to maximize functional recovery and transplanted cell survival, while avoiding the potentially antagonistic acute, proinflammatory microenvironment, remains unknown. Recent work has shown that the intracerebral milieu may affect the efficacy of cell therapy. Shindo et al. found that the intracerebral microenvironment after a mild TBI was more favorable for neural stem cell survival, as compared to severe TBI [9]. Additionally, Molcanyi and colleagues transplanted embryonic stem cells into the injured cortex $72 \mathrm{~h}$ after fluid-percussion injury and identified significant transplanted cell death secondary to macrophage phagocytosis, a key component of the inflammatory response to TBI [10].

Given previous success with acute intracerebral neural stem cell therapy, combined with recent work that has further clarified the intracerebral pro-inflammatory response to injury and novel insight into the relationship between the local milieu and transplanted cell survival, we evaluated transplantation of rat neural stem/ progenitor cells into the area of injury and penumbral area $7 \mathrm{~d}$ after a controlled cortical impact TBI. Immunohistochemistry was used to evaluate intracerebral cell survival/migration. Outcome measures included motor and/or cognitive function recovery. We hypothesized that cells would remain near the area of injury and improve motor and cognitive functional recovery.

\section{MATERIALS AND METHODS}

\section{Isolation, Characterization, and Labeling of Rat Neural Stem Cells}

All protocols involving the use of animals were in compliance with the National Institutes of Health Guide for the Care and Use of Laboratory Animals and were approved by the Institutional Animal Care and Use Committee (protocols HSC-AWC-06-038, 07-055, and 07-113). Rat neural stem cells (NSCs) and the rat NSC flow cytometry characterization kit were purchased from Alphagenix (Alphagenix, Inc., Sioux Falls, SD). The manufacturer's protocol was followed to culture and expand the neural stem cells as neurospheres. Flow 
cytometric immunophenotyping was used to characterize the NSCs with the following markers: Nestin, glial fibrillary acidic protein (GFAP), $\beta$-tubulin III, $2^{\prime}, 3^{\prime}$-cyclic nucleotide $3^{\prime}$-phosphodiesterase (CNPase), and myelin basic protein. Cells between passage 2 and 4 were used. NSCs were labeled with Qtracker 655 cell labeling kit (Invitrogen, Carlsbad, CA) per the manufacturer's protocol. Cell-labeling efficiency was greater than $90 \%$.

\section{Controlled Cortical Impact (CCI) Injury}

A CCI device (eCCI Model 6.3; Custom Design, Richmond, VA) was used to administer unilateral brain injury as described previously [11]. Rats were anesthetized with $4 \%$ isoflurane and a 1:1 mixture of $\mathrm{N}_{2} \mathrm{O} / \mathrm{O}_{2}$ and the head was mounted in a stereotaxic frame. The head was held in a horizontal plane; a midline incision was used for exposure, and a 7to 8-mm craniectomy was performed on the right cranial vault. The center of the craniectomy was placed at the midpoint between bregma and lambda, $\sim 3 \mathrm{~mm}$ lateral to the midline, overlying the tempoparietal cortex. Animals received a single impact of $3.1 \mathrm{~mm}$ depth of deformation with an impact velocity of $6 \mathrm{~m} / \mathrm{s}$ and a dwell time of $150 \mathrm{~ms}$ (moderate-severe injury) at an angle of $10^{\circ}$ from the vertical plane using a 6-mm-diameter impact tip, making the impact orthogonal to the surface of the cortex. An audible baseline monitor was used to ensure that the location of the tip, relative to the surface of the brain, was consistent prior to each impact. The impact was delivered onto the parietal association cortex. Sham injury was performed by anesthetizing the animals, making the midline incision, and separating the skin, connective tissue, and aponeurosis from the cranium, before closing the incision. The body temperature was maintained at $37^{\circ} \mathrm{C}$ by the use of a heating pad. Previously obtained serial arterial $\mathrm{PaO}_{2}$ and $\mathrm{PaCO}_{2}$ have shown that animals do not become hypoxic or hypercarbic during this procedure.

\section{Preparation and Intracerebral Placement of Cells}

After expansion per protocol, cells were collected as neurospheres, gently titurated to break cell groups into single-cell suspensions, and suspended in the phosphate-buffered saline (PBS) vehicle. Cells were checked for viability via Trypan blue exclusion and counted using a hemocytometer. NSCs were then suspended at a concentration of $8000 \mathrm{c} / \mu \mathrm{L}$. Immediately prior to intracerebral cell placement, the cells were titurated gently 8-10 times to ensure a homogeneous mixture of cells.

Seven $\mathrm{d}$ after CCI, rats were again anesthetized as above and the head was mounted in a stereotaxic frame. The midline incision was opened and the injured brain was exposed. A 25-gauge microinjection needle was used to stereotactically guide the placement of the cells in the area of injury and the penumbral area (Fig. 1). At all 10 injection sites, $5 \mu \mathrm{L}$ PBS containing 40,000 NSCs was injected over $10 \mathrm{~s}$ at 2-3 mm below the cortex, for a total placement of 400,000 NSCs per treatment animal. Sham treatment animals underwent identical procedures, with the injections only consisting of the PBS vehicle (see experiment flowchart, Fig. 2).

\section{Immunohistochemistry of Brain Tissue}

At $2 \mathrm{~d}$ and $2 \mathrm{wk}$ following intracerebral cell placement of 400,000 NSCs, coronal brain sections were obtained for immunohistochemistry analysis. After intraperitoneal ketamine 
injections, the thoracic cavity was opened and room-temperature PBS was infused for 15 min via the left ventricle. The heart was spontaneously beating on initiation of infusion and the animals were simultaneously allowed to exsanguinate via right atrium puncture. Cold $4 \%$ paraformaldehyde was then perfused for $15 \mathrm{~min}$ via the left ventricle. The brain was extracted and placed in $4 \%$ paraformaldehyde at $4^{\circ} \mathrm{C}$ for $24-48 \mathrm{~h}$. The brain was embedded in 3\% agarose, sectioned at $50 \mu \mathrm{M}$ in the coronal plane using a vibrating-blade microtome (Leica Microsystems; Bannockburn, IL), stained with 4',6-diamidino-2-phenylindole, dilactate (Invitrogen), and placed on a slide. Two sections from the anterior penumbra, anterior injury, central injury, posterior injury, and posterior penumbra areas of each brain were viewed by 2 members of the research team. Cells per coronal section were counted and the counts were averaged and extrapolated to the entire injury area $(8 \mathrm{~mm})$ and brain. All sections were viewed on a Nikon inverted fluorescent microscope (Model TE-2000-U; Nikon Inc., Melville, NY).

\section{Behavioral Training and Testing}

All members of the research team involved in behavioral experimentation were blinded to the experimental groups. Cells were placed intracerebrally $7 \mathrm{~d}$ after CCI injury. Rats were divided into 3 groups ( $n=6$ rats/group): (1) Sham injury; (2) CCI + intracerebral vehicle placement; (3) CCI + intracerebral placement of 400,000 NSCs (see experiment flowchart, Fig. 2).

\section{Motor, Strength, and Reflex Tasks-Rotarod, Neurological Severity Score, Balance Beam, and Foot Fault}

Beginning $\mathrm{d} 1$ after NSC placement, an accelerating rotarod was used to measure motor balance and coordination. The rotarod consisted of a rotating spindle (diameter, $10 \mathrm{~cm}$ ). All animals were tested using 3 trials per day at d 1-5 after NSC placement. Velocity of the rod was started at $15 \mathrm{rpm}$ and increased $3 \mathrm{rpm}$ every $5 \mathrm{~s}$. Maximum speed maintained prior to failure (fall or inability to stay on the top of the rod) was recorded.

A neurological severity score was determined on d 1-5 after NSC placement. Points are assigned for alterations of motor, behavior, and reflex so that the maximal score of 14 represents severe neurological dysfunction, while a score of 0 indicates normal, intact neurological function. The indices that comprise the neurological severity score have been described in detail previously $[12,13]$.

The ability to balance on a balance beam was assessed on d 1-5 after NSC placement. Animals were placed on a $1.5-\mathrm{cm}$-wide beam for $60 \mathrm{~s}$ or until they fell. Three trials per day were completed.

The ability to traverse chicken wire was also assessed on d 1-5 after NSC placement. Animals were placed on a chicken wire path $10 \mathrm{~cm}$ wide by 5 feet long and left rear foot faults were counted over 50 steps. Three trials per day were completed. 


\section{Cognitive Task—Morris Water Maze (Learning Paradigm)}

Two wk (early) and $10 \mathrm{wk}$ (late) after injury (1 wk and 9 wk after NSC placement), animals were tested in a hidden platform, learning paradigm [12] version of the Morris water maze task $[14,15]$. Animals were tested using 4 trials per day, over 5 consecutive days. Each trial was initiated by placing the animal in 1 of 4 randomly chosen locations, facing the wall of the tank. Animals were allowed to search for the hidden platform for a period of $60 \mathrm{~s}$. If an animal failed to find the platform, the animal was placed there by the experimenter and allowed to remain on the platform for a period of $30 \mathrm{~s}$ before being returned to a warming cage for 4 min between trials. For each trial, movement within the maze was monitored by a video camera linked to tracking software (Chromotrack; San Diego Instruments, San Diego, CA). The latency to platform was calculated as the time necessary to locate the hidden platform. Using the tracking software, we also calculated time spent in the area near the platform and the time spent circle swimming.

\section{Statistical Analysis}

Differences in behavioral testing were assessed by repeated measures analysis of variance with post-hoc Tukey-Kramer analysis. All data are shown as mean \pm SEM.

\section{RESULTS}

\section{Flow Cytometry Characterization of NSCs}

Flow cytometric analysis confirmed that the NSCs were Nestin positive (Fig. 3). Small percentages of cells were also found to express GFAP (astroglial cells) and CNPase (oligodendrocytes and oligodendroglial progenitors).

\section{Immunohistochemistry of Brain Sections after NSC Placement}

Immunohistochemistry analysis revealed that $1.4-1.9 \%$ of infused cells remained in the neural tissue at $48 \mathrm{~h}$ and at $2 \mathrm{wk}$ post placement (Fig. 4). Nearly all cells were located along injection tracks at $48 \mathrm{~h}$. There was an average of 1.3 cell clusters per brain section with $54.38 \pm 16.7$ cells per cluster. Extrapolated to a $1 \mathrm{~cm}$ length, there were 7560 NSCs (1.9\%) present $48 \mathrm{~h}$ after injection. At $2 \mathrm{wk}$ some cell dispersion was apparent. There were 3.44 cell clusters per brain section with $31.13 \pm 8.71$ cells per cluster after $2 \mathrm{wk}$. Extrapolated to a 1 $\mathrm{cm}$ length, there were 5680 NSCs (1.4\%) present. Most of the cells were found in the perilesional cortex. Less than $5 \%$ of the intracerebral cells were identified in the hippocampus. Cell differentiation and in vivo immunophenotype were not evaluated.

\section{Motor and Cognitive Behavioral Testing}

Rotarod motor testing revealed significant increases in maximal speed among NSC-treated rats compared with saline controls at $\mathrm{d} 4(36.4$ versus $27.1 \mathrm{rpm}, P<0.05)$ and 5 (35.8 versus $28.9 \mathrm{rpm}, P<0.05$ ) (Fig. 5). All other motor, as well as early and late cognitive evaluations (Figs. 6 and 7), revealed no significant differences compared to control animals. 


\section{DISCUSSION}

We have shown that intracerebral rat neural stem cell placement $7 \mathrm{~d}$ after a moderate TBI can improve motor but does not appear to improve cognitive function recovery. The cells appear to remain in the brain at 2 and $14 \mathrm{~d}$ after placement. The timing of placement may be an important factor in cell survival and may improve cell survival and motor recovery.

Previous work has shown that acute NSC transplantation may help recovery after TBI. Fetal rodent cortical tissues were first isolated and transplanted into the injured cortical areas of adult rats $24 \mathrm{~h}$ after a fluid percussion injury by Sinson and colleagues [5]. Significant cell transplant survival, interaction between the transplanted cells and the injured brain, along with significant improvements in motor and cognitive function were reported. Subsequent work has confirmed that acute intracerebral placement of various neural progenitor cell populations improves functional recovery $[6,16]$. Recently, primed fetal human neural stem cells transplanted intracerebrally $24 \mathrm{~h}$ after a TBI survive in the brain, secrete significant amounts of GDNF, and mediated improved cognitive function recovery [8]. Their NSCs were placed directly into the hippocampus, resulting in improvements in hippocampaldependent function.

Delayed or subacute transplantation of certain neural stem cell populations has also shown promising results. Transplantation of neural progenitor cells (derived from E14.5 mice) into the striatum $7 \mathrm{~d}$ after a cortical impact injury led to improved motor and cognitive function recovery that was sustained up to a year after transplantation [17]. The transplanted cells were noted throughout the hippocampus and the cortex adjacent to the injury. Neural stem cells (again derived from E14.5 mice) transplanted $1 \mathrm{wk}$ after cortical impact injury were shown to survive and proliferate when transplanted with a fibronectin-based scaffold [18]. They concluded that the environment and the location of cell transplantation play an important role in cell survival and migration. Additionally, human adult neurons were intracerebrally transplanted into rodent brains 1 mo after a fluid percussion injury and were found to survive, although the rate of survival was not quantified nor was any functional recovery identified [19].

The details of cell delivery are critical when discussing cell therapy. Protocol variations such as vehicle volume, vehicle type, injection location, injection speed, and needle withdrawal can alter cell delivery significantly, although there is no consensus on the optimal conditions. Smaller vehicle volumes cause less damage on infusion but may not maintain the cells in a single cell suspension. We chose PBS as the vehicle because of its physiological compatibility, but thicker matrices or gels could improve cell survival/engraftment. We chose our injection strategy to deliver cells to the penumbral area, while minimizing injection locations to minimize the damage from the delivery itself. We injected the cells at approximately $1 \mu \mathrm{L}$ per second and withdrew the needle over $3-5 \mathrm{~s}$ each time.

We specifically evaluated subacute therapy of adult, subventricular zone derived neural stem cells for several reasons. Adult-derived neural stem cells may be more accessible than embrionically derived cells, given current political pressures and concerns about transplant cell rejection, and they are easier to expand than adult neurons. The acute, pro-inflammatory 
response to TBI is an area of ongoing investigation [20,21], and, although the inflammatory response has beneficial effects, it has been shown to have deleterious effects on native cells $[22,23]$ and transplanted cells $[9,10]$. Molcanyi and coworkers found that embryonic stem cells transplanted into the injured cortex $72 \mathrm{~h}$ after fluid-percussion injury did not have a prolonged survival secondary to the highly pro-inflammatory milieu [10]. They found the observed transplanted cell loss to be mediated by activated macrophage phagocytosis of the cells. Although a hyperacute cell transplantation $(<24 \mathrm{~h}$ after injury) strategy has shown cell survival and behavioral benefit $[5-7,16,24]$, recent work is revealing that the acute, central nervous system proinflammatory microenvironment is suboptimal for survival of grafted cells [25]. We chose the 7-d time point because the optimal time window may be after the acute inflammatory cascade, including cytokine release, macrophage/microglia infiltration, and edema (which all appear to resolve around d 5-6 after injury), yet prior to glial scar formation (which is observed to begin forming around d 10-14) [25, 26].

We have shown that subacute intracerebral rat neural stem cell therapy can improve motor recovery. The NSCs appear to remain in the brain at 2 and $14 \mathrm{~d}$. The subacute placement strategy may allow improved cell survival, as the acute, local intracerebral proinflammatory milieu may be suboptimal for cell survival. Continued investigation is necessary to optimize the delivery of cells to the traumatically injured brain.

\section{ACKNOWLEDGMENTS}

This work was supported by Grants T32 GM008792-06 (M.T.H.), MO1 RR 02558, R21 HD 04 2659-01A1, and the Children's Memorial Hermann Hospital Foundation and Texas Higher Education Coordinating Board.

\section{REFERENCES}

1. Kraus JF, Fife D, Conroy C. Pediatric brain injuries: The nature, clinical course, and early outcomes in a defined United States' population. Pediatrics. 1987; 79:501. [PubMed: 3822667]

2. Keel M, Trentz O. Pathophysiology of polytrauma. Injury. 2005; 36:691. [PubMed: 15910820]

3. Consensus conference. Rehabilitation of persons with traumatic brain injury. NIH Consensus Development Panel on Rehabilitation of Persons with Traumatic Brain Injury. JAMA. 1999; 282:974. [PubMed: 10485684]

4. Doppenberg EM, Choi SC, Bullock R. Clinical trials in traumatic brain injury: Lessons for the future. J Neurosurg Anesthesiol. 2004; 16:87. [PubMed: 14676577]

5. Sinson G, Voddi M, McIntosh TK. Combined fetal neural transplantation and nerve growth factor infusion: Effects on neurological outcome following fluid-percussion brain injury in the rat. J Neurosurg. 1996; 84:655. [PubMed: 8613859]

6. Riess P, Zhang C, Saatman KE, et al. Transplanted neural stem cells survive, differentiate, and improve neurological motor function after experimental traumatic brain injury. Neurosurgery. 2002; 51:1043. discussion 1052. [PubMed: 12234415]

7. Wennersten A, Meier X, Holmin S, et al. Proliferation, migration, and differentiation of human neural stem/progenitor cells after transplantation into a rat model of traumatic brain injury. $\mathbf{J}$ Neurosurg. 2004; 100:88. [PubMed: 14743917]

8. Gao J, Prough DS, McAdoo DJ, et al. Transplantation of primed human fetal neural stem cells improves cognitive function in rats after traumatic brain injury. Exp Neurol. 2006; 201:281. [PubMed: 16904107]

9. Shindo T, Matsumoto Y, Wang Q, et al. Differences in the neuronal stem cells survival, neuronal differentiation and neurological improvement after transplantation of neural stem cells between mild and severe experimental traumatic brain injury. J Med Invest. 2006; 53:42. [PubMed: 16537995] 
10. Molcanyi M, Riess P, Bentz K, et al. Trauma-associated inflammatory response impairs embryonic stem cell survival and integration after implantation into injured rat brain. J Neuro-trauma. 2007; 24:625.

11. Lighthall JW. Controlled cortical impact: A new experimental brain injury model. J Neurotrauma. 1988; 5:1. [PubMed: 3193461]

12. Fujimoto ST, Longhi L, Saatman KE, et al. Motor and cognitive function evaluation following experimental traumatic brain injury. Neurosci Biobehav Rev. 2004; 28:365. [PubMed: 15341032]

13. Mahmood A, Lu D, Wang L, et al. Treatment of traumatic brain injury in female rats with intravenous administration of bone marrow stromal cells. Neurosurgery. 2001; 49:1196. discussion 1203. [PubMed: 11846913]

14. Guzowski JF, McGaugh JL. Antisense oligodeoxynucleotide-mediated disruption of hippocampal cAMP response element binding protein levels impairs consolidation of memory for water maze training. Proc Natl Acad Sci USA. 1997; 94:2693. [PubMed: 9122258]

15. Schenk F, Morris RG. Dissociation between components of spatial memory in rats after recovery from the effects of retrohippocampal lesions. Exp Brain Res Exp Hirnforschung. 1985; 58:11.

16. Bakshi A, Shimizu S, Keck CA, et al. Neural progenitor cells engineered to secrete GDNF show enhanced survival, neuronal differentiation and improve cognitive function following traumatic brain injury. Eur J Neurosci. 2006; 23:2119. [PubMed: 16630059]

17. Shear DA, Tate MC, Archer DR, et al. Neural progenitor cell transplants promote long-term functional recovery after traumatic brain injury. Brain Res. 2004; 1026:11. [PubMed: 15476693]

18. Tate MC, Shear DA, Hoffman SW, et al. Fibronectin promotes survival and migration of primary neural stem cells transplanted into the traumatically injured mouse brain. Cell Transplant. 2002; 11:283. [PubMed: 12075994]

19. Zhang C, Saatman KE, Royo NC, et al. Delayed transplantation of human neurons following brain injury in rats: A long-term graft survival and behavior study. J Neurotrauma. 2005; 22:1456. [PubMed: 16379583]

20. Arvin B, Neville LF, Barone FC, et al. The role of inflammation and cytokines in brain injury. Neurosci Biobehav Rev. 1996; 20:445. [PubMed: 8880734]

21. Allan SM. The role of pro- and antiinflammatory cytokines in neurodegeneration. Ann NY Acad Sci. 2000; 917:84. [PubMed: 11268414]

22. Morganti-Kossmann MC, Rancan M, Stahel PF, et al. Inflammatory response in acute traumatic brain injury: A double-edged sword. Curr Opin Crit Care. 2002; 8:101. [PubMed: 12386508]

23. Shohami E, Ginis I, Hallenbeck JM. Dual role of tumor necrosis factor alpha in brain injury. Cytokine Growth Factor Rev. 1999; 10:119. [PubMed: 10743503]

24. Kelly S, Bliss TM, Shah AK, et al. Transplanted human fetal neural stem cells survive, migrate, and differentiate in ischemic rat cerebral cortex. Proc Natl Acad Sci USA. 2004; 101:11839. [PubMed: 15280535]

25. Okano H. Stem cell biology of the central nervous system. J Neurosci Res. 2002; 69:698. [PubMed: 12205662]

26. Harting MT, Jimenez F, Adams SD, et al. Acute, regional inflammatory response after traumatic brain injury: Implications for cellular therapy. J Surg Res. 2008; 144:425. 


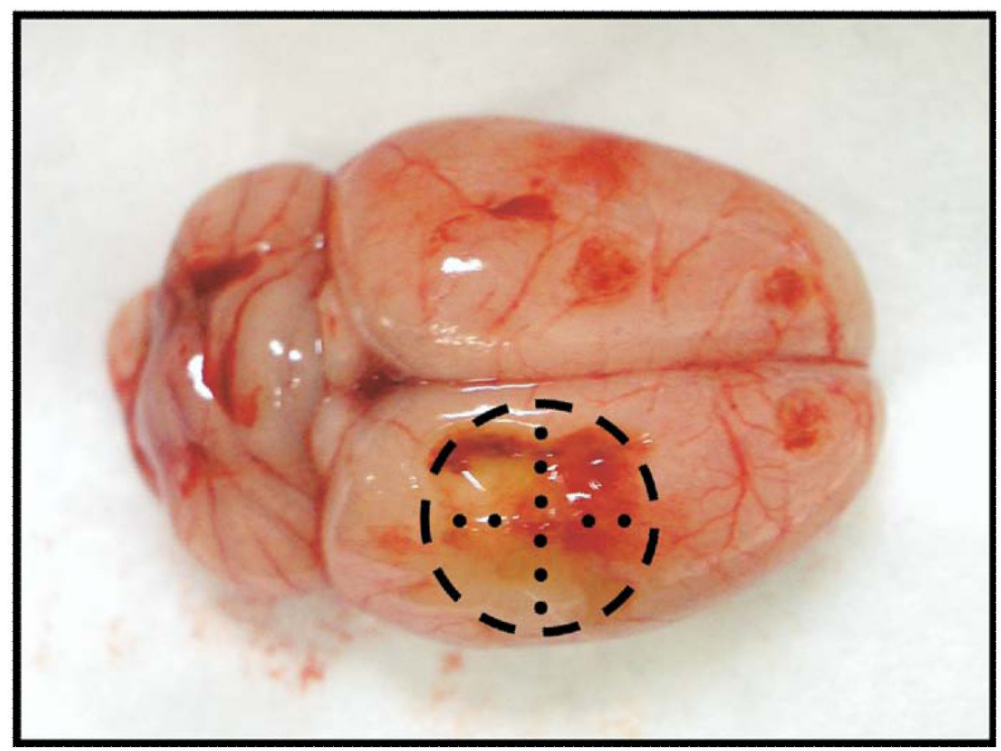

FIG. 1.

Intracerebral placement of NSCs. The dashed circle represents the location of the craniotomy and the black dots are locations of NSC injection. At each injection site, 40,000 NSCs in $5 \mu \mathrm{L}$ of saline vehicle were injected 2-3 mm below the cortex surface. (Color version of figure is available online.) 


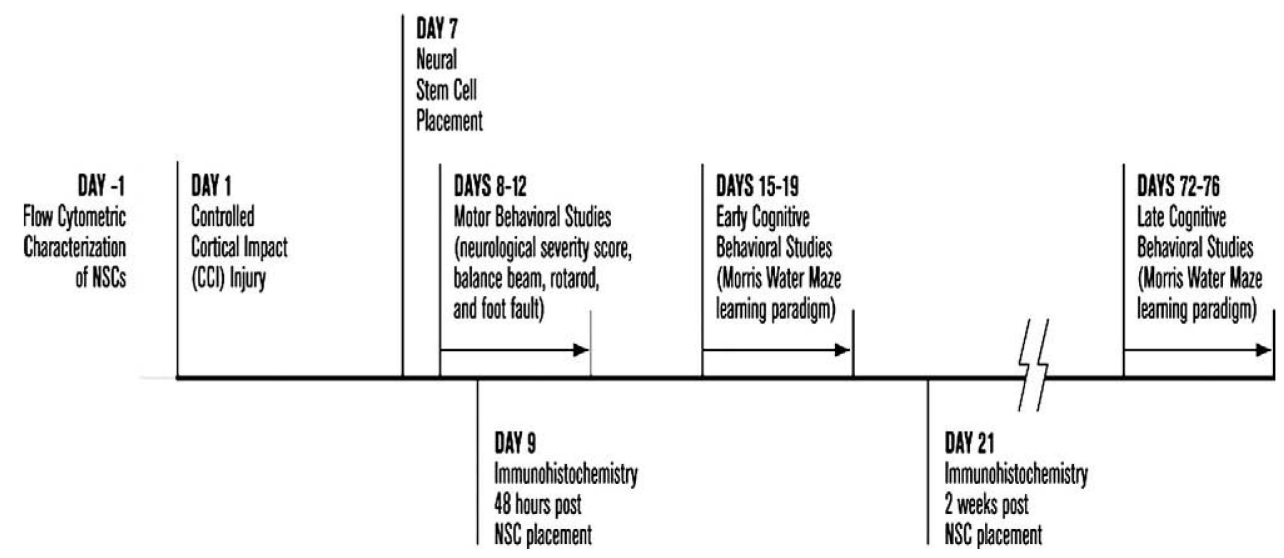

FIG. 2.

Flowchart outlining the timing of the experiments. 

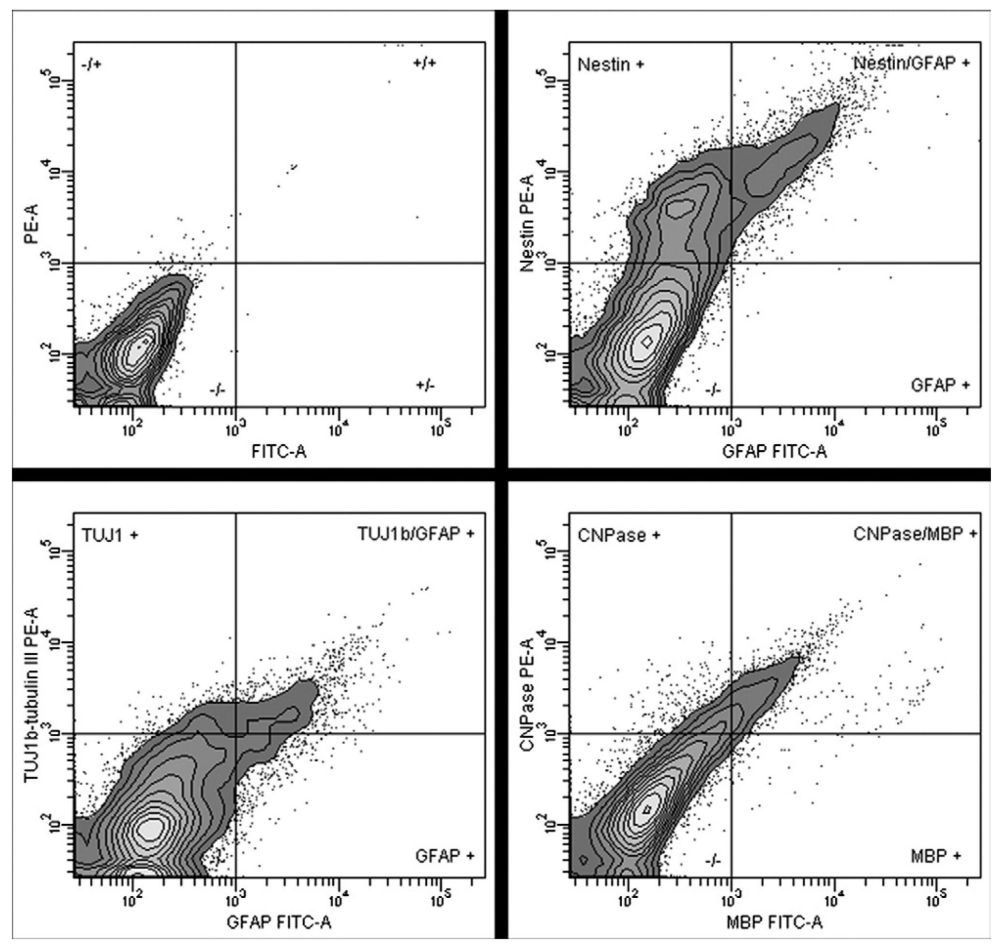

FIG. 3.

Flow cytometric immunophenotyping of rat neural stem cells (rNSC). The rNSCs were immunophenotyped for the following receptors/proteins: Nestin, GFAP, $\beta$-tubulin III, CNPase and myelin basic protein (MBP). Cells were found to be Nestin-positive and mildly positive for GFAP and CNPase. 


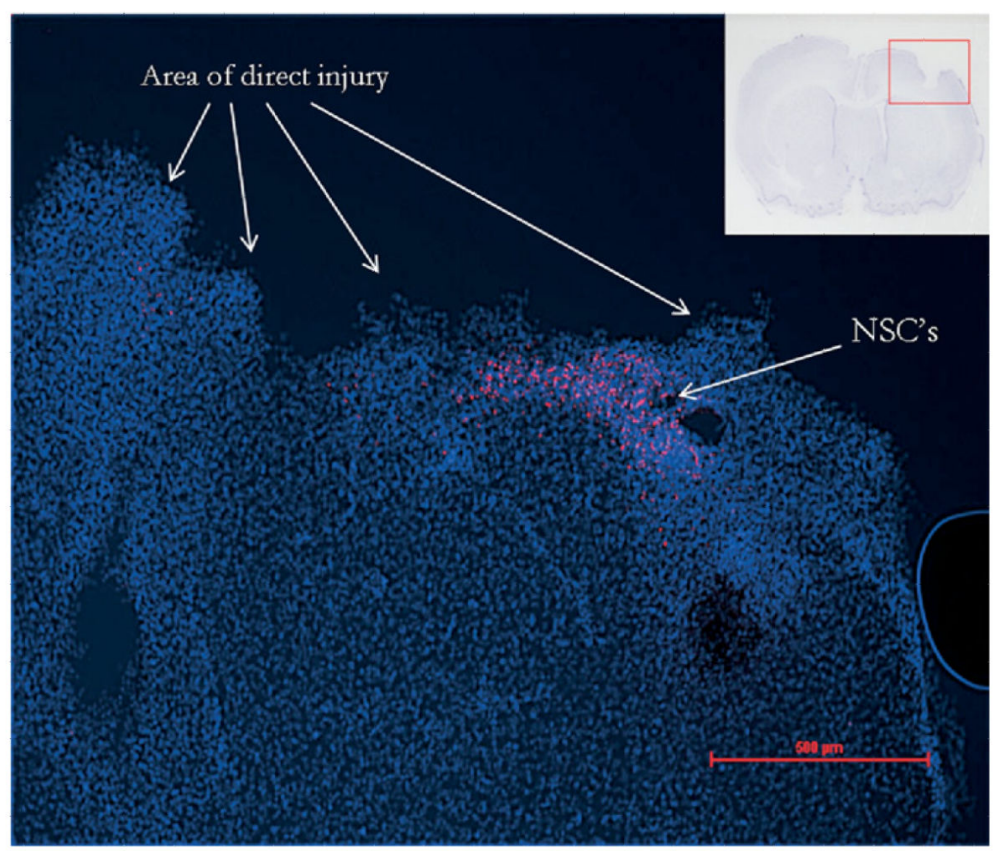

FIG. 4.

Immunohistochemistry of brain $48 \mathrm{~h}$ after CCI injury and rNSC placement. At $48 \mathrm{~h}$ after injury, numerous rNSCs are seen in the penumbral cortex. The nuclei are stained with 4',6diamidino-2-phenylindole, dilactate (blue), and the rNSCs are stained with Qtracker 655 (red). The insert shows an entire coronal section after Nissl staining, with a red box outlining an area similar to the magnified image. (Color version of figure is available online.) 


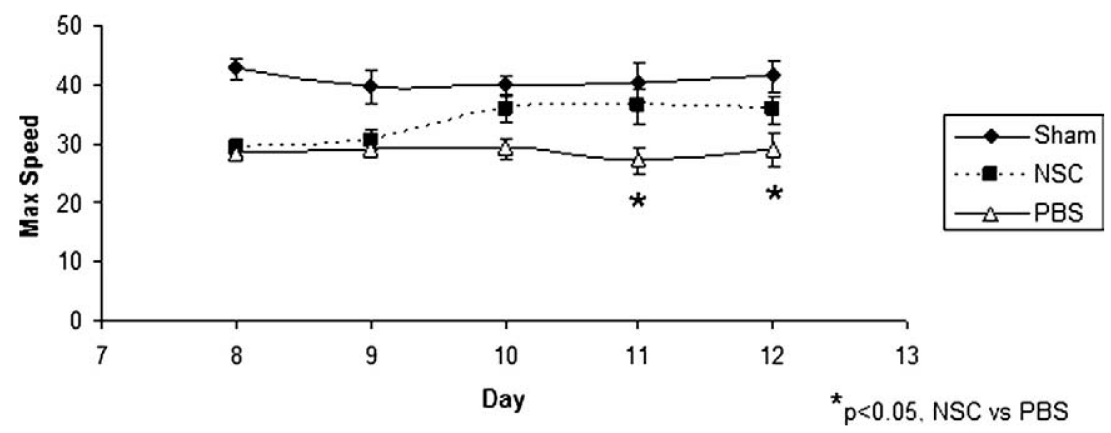

FIG. 5.

Rotarod motor testing results. Rats were tested using 3 trials per day at d 8-12 (d 1-5 after NSC placement). Velocity of the rod was started at $15 \mathrm{rpm}$ and increased $3 \mathrm{rpm}$ every $5 \mathrm{~s}$. Maximum speed ( $y$-axis) maintained prior to failure (fall or inability to stay on the top of the rod) was recorded. On d 4 and 5, rats that received rNSCs were able to remain on the rotarod at a significantly increased speed relative to rats who received vehicle injection. 


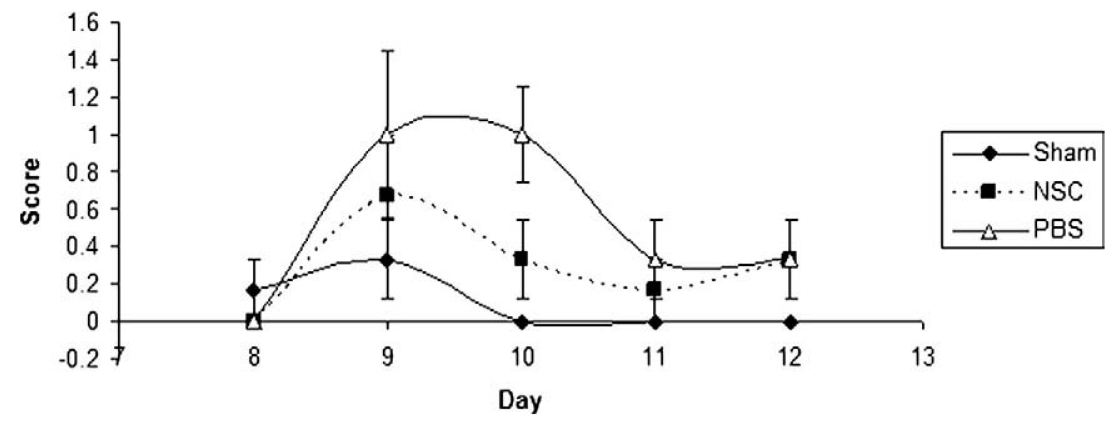

FIG. 6.

Neurological severity score (NSS) results. Rats were evaluated for global neurological function using the previously described NSS on d 8-12 (d 1-5 after NSC placement). No statistically significant differences were identified. 

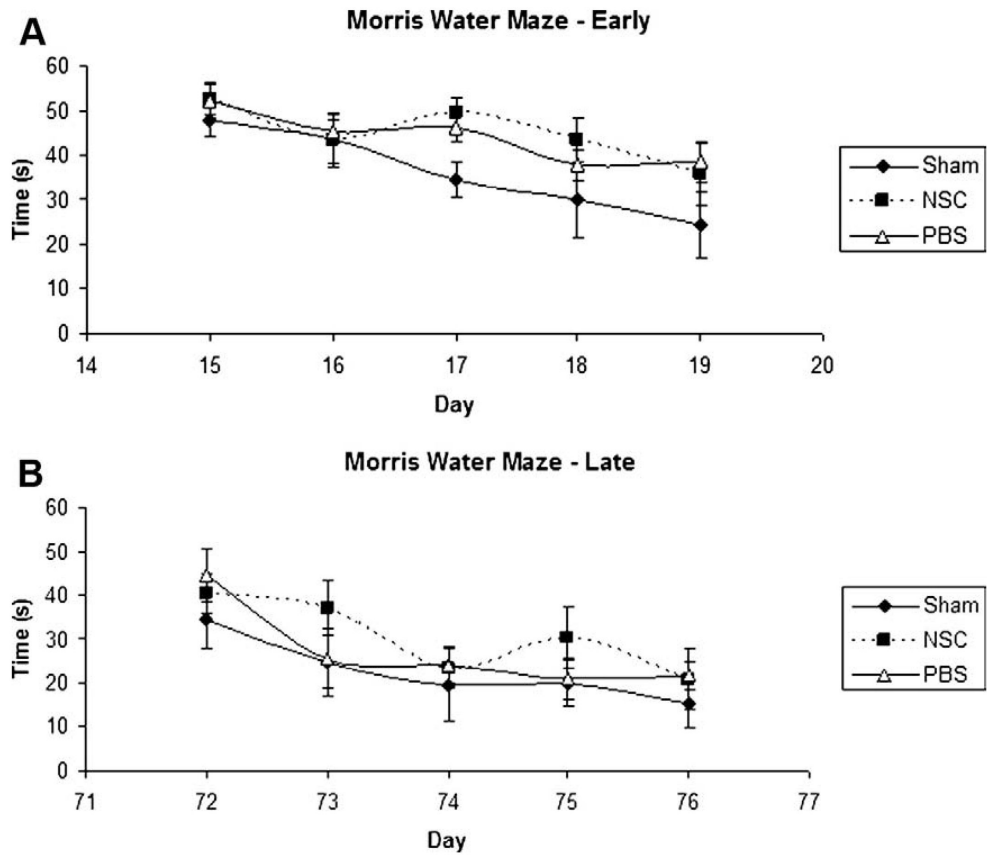

FIG. 7.

Morris water maze results. Two wk (early, A) and $10 \mathrm{wk}$ (late, B) after injury (1 wk and 9 wk after NSC placement), animals were tested in a hidden platform, learning a paradigm version of the Morris water maze task. Animals were tested using 4 trials per day, with latency to the hidden platform ( $y$-axis) recorded after each trial. No statistically significant differences were identified. 